\title{
Potential Impacts of Agritourism in South Miami-Dade County 1
}

\section{Edward Evans and Alan Hodges ${ }^{2}$}

As the impacts of trade liberalization and globalization continue to unfold, many agricultural producers are finding it extremely difficult to sustain their current levels of profits, let alone increase profit margins. Caught in a price-cost squeeze situation, with declining or stagnating prices concomitant with rising input costs, agricultural producers are looking for alternatives to replace or supplement traditional farm operations, hoping to reverse the steady erosion in net farm income. One increasingly popular alternative in some areas of the United States is agritourism.

Agritourism is broadly defined as the integration of tourism into current agricultural food and fiber product operations in such a way for the farm or ranch to "grow" and supplement its income as well as increase recreational diversity for the public (Maetzoid, 2004). More specifically, it is any business or activity that invites visitors (including local residents) to a farm or ranch to enjoy agriculture and natural resources. This may include any of the following: farm and specialty product markets; product processing, including wineries; fairs, festivals, and special events; petting or riding activities involving horses or other farm animals; unique dining experiences; wildlife; fishing; floriculture; educational programs; heritage/cultural/ethnic programs; arts and crafts; farm/ranch vacations; tours and touring; and pick/cut/gather/grow-your-own activities (Mahoney, 1999).

While the concept of combining agriculture and tourism is not new, it is becoming increasingly popular due to the wide range of potential benefits it may offer to individuals as well as the local and state economy. Potential benefits include:

- Opportunities to increase farm/ranch profitability from agricultural "value added" activities.

- Opportunities to educate the public about the importance of agriculture and its contribution to the economy and quality of life.

- Opportunities to reduce friction in the agricultural-urban interface by demonstrating how agriculture can conserve natural resources.

1. This is EDIS document FE637, a publication of the Food and Resource Economics Department, Florida Cooperative Extension Service, Institute of Food and Agricultural Sciences, University of Florida, Gainesville, FL. Published May 2006. Please visit the EDIS website at http://edis.ifas.ufl.edu.

2. Edward Evans, Assistant Professor, Food and Resource Economics Department, Tropical Research and Education Center, Homestead, FL; and Alan Hodges, Associate-In, Food and Resource Economics Department, Florida Cooperative Extension Service, Institute of Food and Agricultural Sciences, University of Florida, Gainesville, FL. 
- Opportunities to increase demand for locally grown produce using a multiplier effect to stimulate local economic activities.

While both tourism and agriculture are major economic activities in Miami-Dade County, relatively little has been done to integrate the two. A 2002 survey of agricultural producers in the area found that they were reluctant to engage in agritourism activities due to legal, environmental, and safety concerns. The study noted, however, that despite these concerns, about $45 \%$ of the survey respondents indicated they would participate in an agritourism program. The study recommended that the state or county appoint an advisory work-group or coordinator to promote agritourism in the county and to address the concerns of agricultural producers. The study concluded that an effective and dynamic agritourism program could significantly enhance agricultural sales in the area, particularly for small operations, as well as provide additional jobs in the county (Stevens, Degner, and Morgan, 2002).

This study builds on a previous analysis to quantify the potential economic benefits of promoting agritourism in South Miami-Dade County, Florida. IMPLAN, a computer software package that enables construction of local input-output models and associated databases, was used to quantify the potential economic impacts in this study.

\section{Miami-Dade Agricultural Industry}

The 2002 Census of Agriculture showed that Miami-Dade County had about 90,000 acres allocated to agriculture, distributed among 2,244 growers. Of the total farms, $63 \%$ were less than 10 acres and $89 \%$ were less than 50 acres. In 2002, the market value of agricultural products sold in Miami-Dade County was about $\$ 578$ million, representing an increase of $37.2 \%$ since 1997. In shares of production value, the nursery, greenhouse, floriculture, and sod group dominated with an over $75 \%$ share, followed by the vegetable, melon, potato and sweet potato group (17.8\% share), and the fruit, tree nut, and berry group (6.2\% share). The overall economic impact of these sales was about $\$ 2.2$ billion in output (Table 1).
A wide array and assortment of fruits, vegetables, and ornamental products are produced in Miami-Dade County. Approximately 23 species of tropical fruits and 25 species of vegetables and herbs of commercial importance are grown in the area and literally hundreds of different species of ornamental plants.

Yet despite such diversity of products, net returns to growers have been decreasing since 1997 due to factors such as the rising costs of inputs and declining or stagnant prices received from the sale of agricultural commodities. Based on Census of Agriculture data, Figure 1 illustrates this disturbing trend by showing inflation-adjusted average farm gross cash receipts, production expenses, and net cash farm income for agricultural producers in Miami-Dade County over the period 1987 to 2002. The data clearly indicate that while average gross receipts and production expenses have been trending upwards, net farm income has been declining since 1997. With the possible exception of the nursery industry, the major impact on farm or ranch income has been trade liberalization, which has depressed primary agricultural commodity prices while having little or no effect on rising production costs.

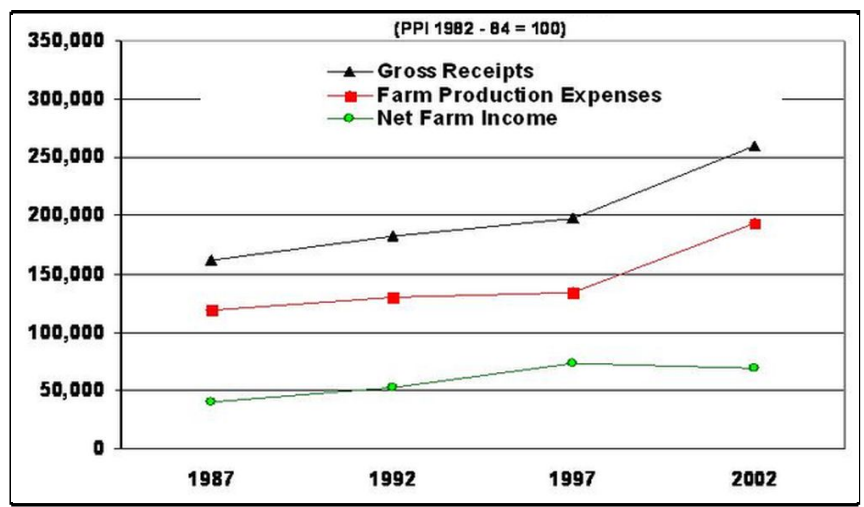

Figure 1. Inflation adjusted average per farm receipts, production expenses, and net income for Miami-Dade County, Florida, 1987-2002 (dollars)

Another disturbing trend has been a noticeably widening farm-retail price spread (i.e., the difference between the prices agricultural producers receive and the prices consumers pay) that has been occurring due to increased consumer demand for off-farm marketing services (e.g., convenience and ready-to-eat foods) and food retailing consolidation. It therefore seems logical that one way agricultural 
producers might enhance their income and increase their share of the consumer dollar is by tapping into retail marketing through direct sales, processing, packaging, and value added activities.

\section{Miami-Dade Tourist Industry}

Tourism is Miami-Dade County's most important economic industry. According to the Greater Miami Convention and Visitors Bureau (GMCVB), more than 11 million overnight visitors traveled to Miami-Dade County in 2005 and spent an estimated $\$ 13.35$ billion (Table 2). Of this total, roughly half ( $\$ 6.56$ billion) was spent on accommodations and food services, followed by retail trade $(28.3 \%)$ and arts/entertainment/recreation (15\%). The $\$ 13.85$ billion spent by tourists had an estimated total economic output impact of $\$ 32.7$ billion on the Miami-Dade County economy, including the indirect and induced multiplier effects. This implies that each dollar spent by tourists has the potential to generate an additional $\$ 1.40$ of local economic activity. In terms of employment and taxes, a total of 417,122 jobs and $\$ 2.12$ billion in indirect business taxes were generated. Note that these impacts represent only air travel visitors to the Miami-Dade County area, and do not include visitors traveling by automobile or other ground transportation. Combining this large tourism industry with the uniqueness and diversity of local agriculture may provide significant opportunities for farmers to diversify their operations and their revenue sources.

\section{Examples of Economic Impact from Agritourism}

As mentioned earlier, there is growing evidence of benefits from agritourism and many states have developed programs as highlighted below:

- Vermont: The most recent survey by the New England Agricultural Statistics Service reveals that the total annual income from agritourism increased 86\% ( $\$ 19.5$ million) between 2000 and 2002 (about $4 \%$ of the state's total gross farm income generated in 2002). Approximately 2,300 Vermont farms (about one-third of the state's total) are engaged in agritourism, generating on average nearly $\$ 8,900$ in agritourism income per farm annually (farms with 500 acres or more produce an average of $\$ 15,300$ ). In addition, the Vermont Farms Association's website lists 20 farms that offer overnight stays with home-cooked meals. For example, Liberty Hill Farm (in Rochester), one of the leading agritourism farms in the state, charges roughly $\$ 250$ per night for a family to stay on the farm and "help" with farm chores (Notebook, 2005).

- San Diego County, California: A study of visitors to The Flower Fields in Carlsbad (a popular agritourism attraction in San Diego County) shows a positive economic impact for The Flower Field farm operation and the city of Carlsbad. At the farm level, an estimated 150,000 paid admissions resulted in $\$ 600,000$ of additional revenue for the operation. Also, the influx of visitors increased direct marketing of ranunculus (buttercup) bulbs and other products grown by the operation or by other local farmers, thereby increasing profit margins. This identity and name recognition facilitated the launch of other value-added, revenue-generating activities, including the introduction of a new line of plant material and the sale of souvenirs with the trade name The Flower Fields. More importantly, agritourism has been instrumental in providing educational information about local agriculture and how it can enhance the natural beauty of the area. The economic benefits to the community have been sizable. Direct expenditures by visitors to The Flower Fields totaled about \$2.3 million in Carlsbad and \$7.76 million in San Diego County (Lobo et al, 2005)

- Hawaii: The value of Hawaii's agritourism activities in 2003 was estimated at $\$ 33.9$ million, an increase of $30 \%$ (\$26 million) since 2000. The report states that while only 187 (3.4\%) of the total 5,500 farms in Hawaii currently are engaged in agritourism business activities (this represents a $48 \%$ increase in participation over 2000 ), interest in agritourism is growing. Another 145 farms (a 77.5\% increase) either started agritourism activities in 2004 or will do so in the near future. Farms of all sizes, ranging from those with sales of less than $\$ 2,500$ to those with sales above $\$ 1$ million, are participating in agritourism. In terms of the breakdown of 
revenues generated from agritourism, on-farm sales direct to farm visitors was the leading category, accounting for $\$ 13.5$ million (roughly $40 \%$ of total revenues), followed by retail sales of products from other farms and souvenir items (26.8\%); outdoor recreation (14.8\%); accommodations (7.4\%); education, including farm tours (3.5\%); and entertainment (3.1\%). The report also notes that many operations received orders for agritourism products after visitors returned home (Hawaii Agricultural Statistical Office, 2004).

\section{Assessment of Potential Impacts of Agritourism in South Miami-Dade}

As noted earlier, Miami-Dade County has a total of 2,244 farms, producing a wide range of ornamental, vegetable, and tropical fruit crops. Given the relatively close proximity of the farming community to major tourist attractions, there appears to be considerable opportunities for, and benefits to be derived from, linking the two sectors.

Data obtained from the Tropical Everglades Visitors Association (TEVA) and GMCVB indicate that on average about $10 \%$ of overnight visitors to Miami-Dade County stay in South Miami-Dade, and that approximately $2 \%$ of all visitors visit the Everglades National Park (Brian Conesa, executive director, Tropical Everglades Visitor Association, personal communication, 2006). By using these estimates and applying them to the 2005 Miami-Dade visitor statistics, it can be implied that about 1.13 million visitors stayed in South Miami-Dade, and that about 226,000 visitors visited the Everglades and other Parks in the area. Moreover, assuming the same spending pattern as that observed for the entire county, the 1.13 million visitors staying in South Miami-Dade would have spent approximately $\$ 1.39$ billion, with $\$ 3.27$ billion in overall economic impacts on the local economy; however, much of this spending would have been captured by non-agricultural sectors.

To better asses the potential for agritourism we consider two scenarios. Scenario I assumes that $1 \%$ of the total spending by visitors to Miami-Dade County is retained in the farming community due to agritourism activities. This implies total revenue of $\$ 139$ million (1\% of $\$ 13.9$ billion), or the equivalent of total spending by 113,000 visitors. This assumption is plausible considering that $2 \%$ $(226,000)$ of these tourists visited the Everglades in 2005.

Since it has been estimated that each dollar spent by tourists has the potential to generate another $\$ 1.40$ (multiplier of 2.40), the total economic impact on the local economy would be about $\$ 336$ million. It would generate an additional 4,000 full-time jobs and about $\$ 21$ million in indirect business taxes to state and local governments.

Scenario II is based on the experience of agritourism in Hawaii. Both Hawaii and Miami-Dade County have major tourist attraction areas that are relatively close to farming communities. Although there are some distinct differences between the two areas, including the types of commodities grown and the size distribution of the farms, the analysis assumes that the average spending per farm participating in agritourism in Miami-Dade County $(\$ 182,000)$ is about the same as that in Hawaii. It further assumes that a total of 224 farms (10\%) take part in agritourism activities. This assumption is justified on the basis of the earlier analysis (EDIS FE359) which indicated a willingness on the part of $45 \%$ of respondents to participate in an agritourism program. This would generate total revenues of $\$ 40.7$ million, with an overall economic impact on the local economy of about $\$ 97.7$ million (2.4 x $\$ 40.7$ million). This would also generate total employment of 1,200 full-time jobs and \$6.0 million in indirect business taxes.

\section{Concluding Remarks}

With most agricultural producers in Miami-Dade County experiencing increased pressure by developers to sell their lands, rising operating costs, and stagnant or declining profit margins for most of the major agricultural commodities, agritourism is a possible way to assist with preserving agriculture and open space and contributing to the longer- term economic variability of farm operations. Moreover, while the benefits of agritourism are vital to the individual producers, the benefits go much further, 
and with multiplier effects can have major impacts on the local economic economy.

Our conservative assessment of the potential impact from agritourism activities in South Miami-Dade County reveals a direct benefit to the farming community of $\$ 41$ million to $\$ 139$ million, and an overall economic impact of $\$ 98$ million to $\$ 336$ million. While attaining such benefits is possible, realizing them will require a systematic and sustained effort to make agricultural producers become more aware of these potential opportunities; assisting them with development of their enterprises; addressing issues that might arise from time to time, such as signage; and marketing the entire initiative.

\section{References}

Conesa, Brian (executive director, Tropical Everglades Visitor Association). 2006. Personal communication. Tropical Everglades Visitor Association, Florida City, FL. http://tropicaleverglades.com/.

Hawaii Statistical Office. 2004. Hawaii Ag-Tourism. Hawaii Agricultural Statistics, Honolulu, HI.

http://www.nass.usda.gov/hi/speccrop/agtour.htm.

Lobo, R., G. Goldman, D. Jolly, B. Walker, W. Schrader, and S. Parker, 1999. Agritourism Benefits Agriculture in San Diego County. Small Farm Center, University of California at Davis. Reprinted from California Agriculture (November-December). http://www.sfc.ucdavis.edu/agritourism/ agritourSD.html.

Maetzold, J. 2004. Natural Resources Conservation Service, USDA, Washington, D.C.: Alternative Enterprises and Agritourism: Farming for Profit and Sustainability Resource Manual. http://www.nrcs.usda.gov/technical/RESS/ altenterprise/resmanual.html.

Mahoney, E., D. Spotts, and J. Edwards. 1999. Developing Agriculture and Natural Resource Products Tourism by Sustaining and Enhancing Partnership. Unpublished report prepared for the Natural Resources Conservation Service, United States Department of Agriculture, Washington, D.C.
Notebook, 2005. Agritourism: Putting a Face on Northeast Agriculture. http://www.farmcreditmaine.com/notebook/L3/ agritourism.htm.

Stevens, T., R. Degner, and K. Morgan. 2002. Agricultural Producer Attitudes Toward Agritourism in Miami-Dade County, Florida, Electronic Data Information Source (EDIS) FE359, Food and Resource Economics Department, University of Florida, Gainesville, FL. http://edis.ifas.ufl.edu/FE359. 
Table 1. Economic impact of Miami-Dade agriculture.

\begin{tabular}{|lccc|}
\hline \hline Agriculture Industry Group & $\begin{array}{c}\text { Sum of Output } \\
\text { Impacts }\end{array}$ & $\begin{array}{c}\text { Sum of Employment } \\
\text { Impacts }\end{array}$ & $\begin{array}{c}\text { Sum of Total Value Added } \\
\text { Impacts }\end{array}$ \\
\hline $\begin{array}{l}\text { Agricultural Inputs \& Services } \\
\text { (fertilizers, pesticides, veterinary, } \\
\text { support activities) }\end{array}$ & 411 & 6,890 & 7 \\
$\begin{array}{l}\text { Environmental Horticulture } \\
\text { (nursery \& greenhouse, landscape } \\
\text { services) }\end{array}$ & 1,496 & 20,116 & 36 \\
$\begin{array}{l}\text { Fruit \& Vegetable Farming \& } \\
\text { Processing }\end{array}$ & 383 & 3,200 & 11 \\
Other Crop Farming & 11 & 100 & 0 \\
Grand Total & 2,201 & 30,306 & 55 \\
\hline \hline
\end{tabular}




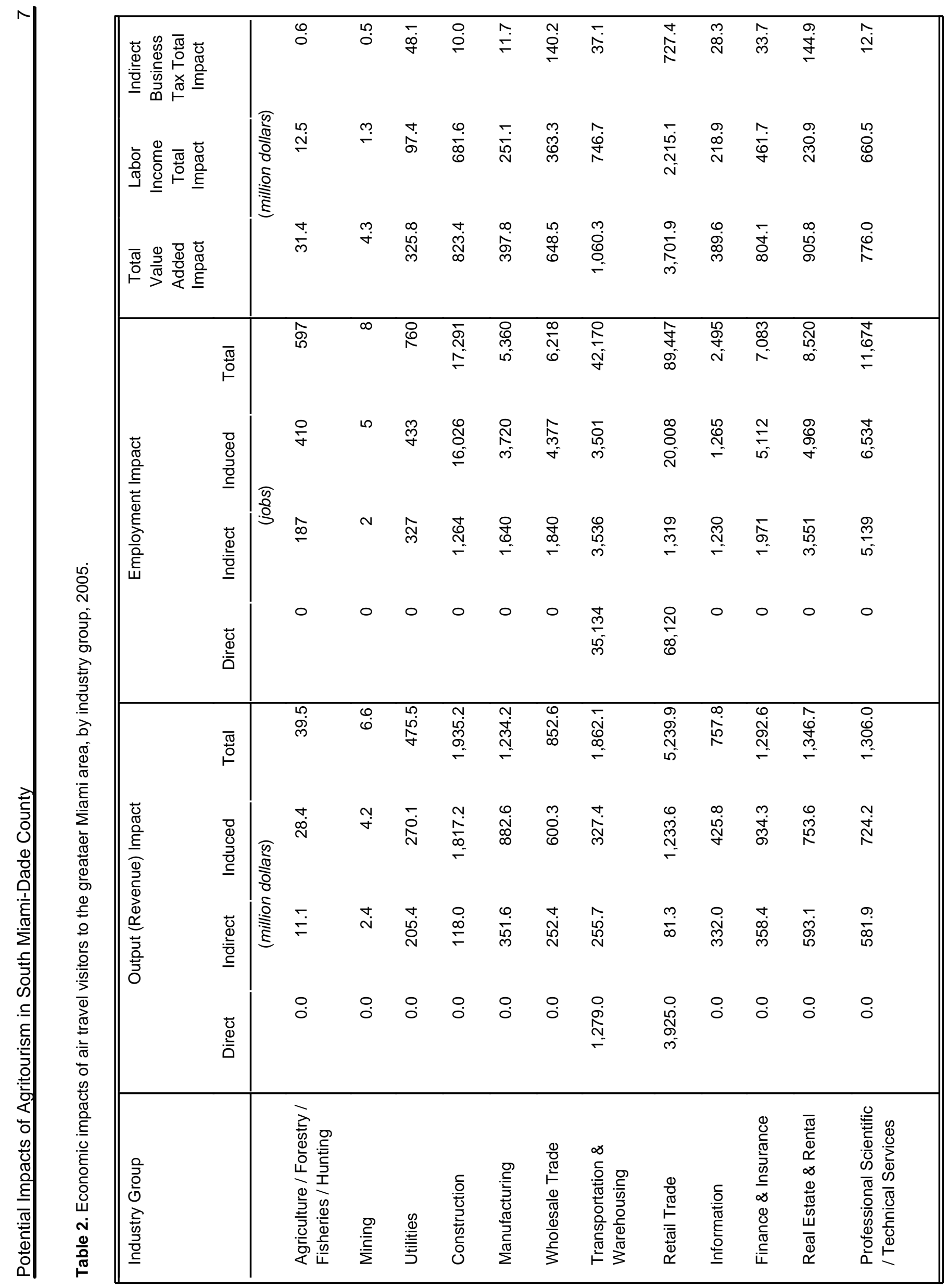




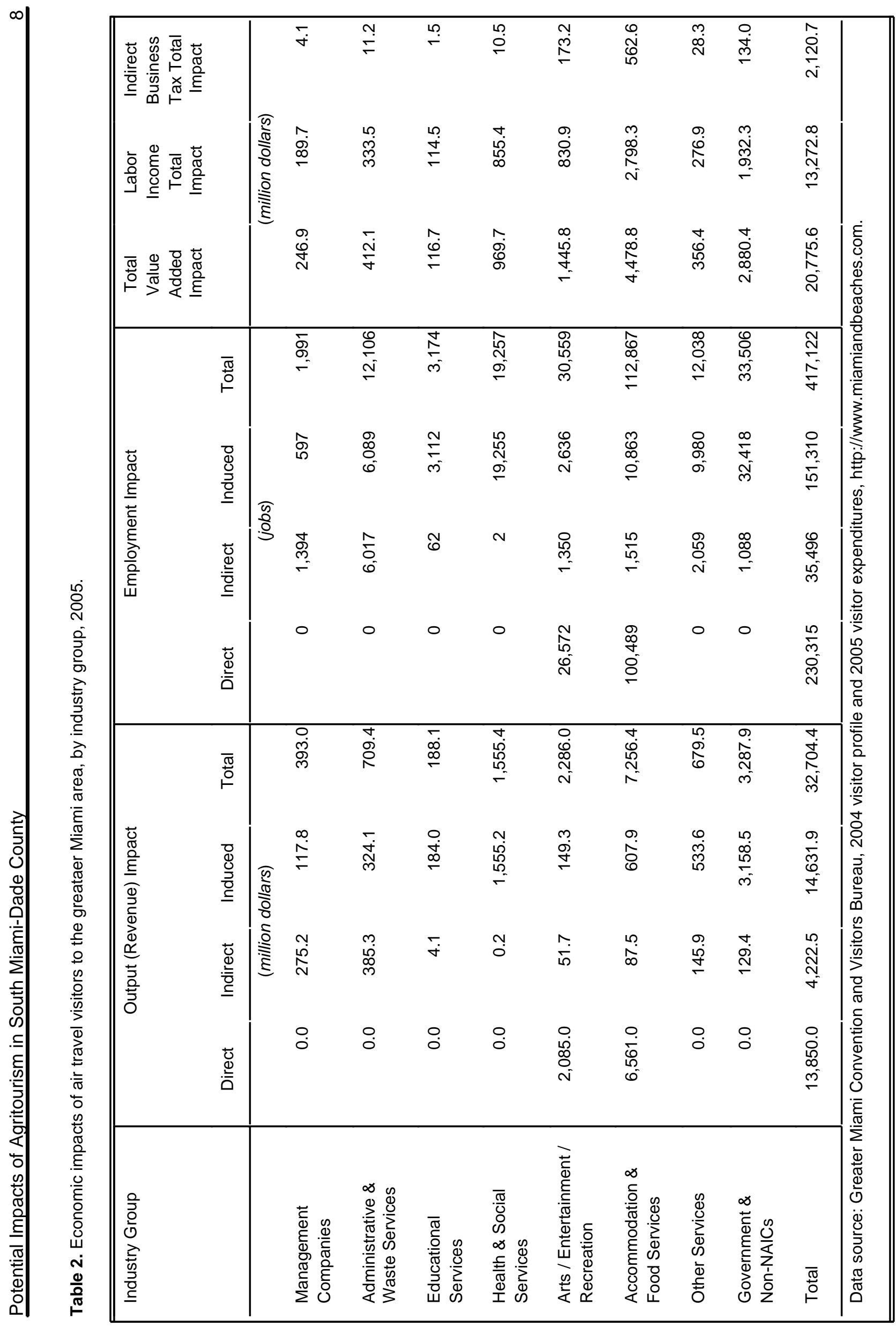

